\title{
Expand the Role of Training in the School of Physical Education Reform and Development
}

\author{
WANG Wei \\ Wuchang Institute Of Technology, Wuhan, 430065, China
}

Keywords: Outward Bound, Physical Education, Reform, Applications, Trends, Teaching Reform.

\begin{abstract}
In this paper, literature, comprehensive analysis, we analyzed the relationship between the origin of Outward Bound, characteristics and school sports and human survival and development, pointed out that school sport is of great significance in the development of human ability to survive in. Combined with domestic and international stage school sport of survival to expand training, Outward Bound survival discussed prospects for the development of school sports and "from small and large, from simple to complex, from the inside out" development mode. Outward Bound including simple physical training, survival training, mental training, personal training, management training, and school sports in which training objectives, terms of training content, training, formation evaluation system have a lot in common will expand scientific and reasonable training introducing them to the school sports, to better promote the overall development of students, improve the quality of school sports. Movement of Skills curriculum objectives - learning and application of sports skills and the development and utilization of curriculum resources, to expand into the school sports training provides the basis for the theory and policy. This article describes the basics of Outward Bound, Outward Bound elaborated into the significance and feasibility of the school sports and expand the training of teaching practice procedures and make recommendations, hoping to expand into the early training school sports play a catalytic role.
\end{abstract}

\section{Introduction}

With the progress of modern society, the sustainable development of the knowledge economy, social demand for talent is increasing. Only has a wealth of knowledge, good health has been insufficient to meet the increasingly fierce competition, good psychological quality, excellent sense of team, hard-working quality and so more and more important due to the development of modern society to put forward new personnel training requirements. as an important part of school education school sports, shouldering the new mission and responsibility to expand the domestic preliminary development training was in keeping with a good supplement school sports reform and development and how will extend into the school sports training among sports teachers facing the issue.

Outward Bound aims to enable participants to challenge themselves, melting team; self-understanding, to stimulate potential; improve relations, positive; build a team, the pursuit of performance; relieve stress, to face the difficulties.

Outward Bound salient features:

- Comprehensive activity. Expand the training to all projects to guide physical activity, triggering a cognitive activity, emotional events, activities and exchanges will have a clear course of action, ask participants to devote all our energies.

- Challenge the limit. Expand the training project has a certain degree of difficulty, and in the psychological test, required students to challenge the limits of their abilities, across the "limit."

- Collective personality. Outward Bound implement group activities, emphasizing the collective cooperation. Each participant tries to make every effort for the collective fight for honor, while drawing enormous strength and confidence from the collective, the display in the collective personality.

- In overcoming difficulties, after the successful completion of course requirements, students can appreciate the heartfelt sense of victory and pride get a rare peak experience of life. 
- Self-education. Just before class teachers to the course content, objectives, requirements, and necessary safety precautions make it clear to the participants, activities, generally not to talk, do not participate in the discussion, with full respect for the dominant position of students and initiative. In summary, even after school, the teacher did not go beyond the main terms of their own to enable trainees to achieve the purpose of self-education.

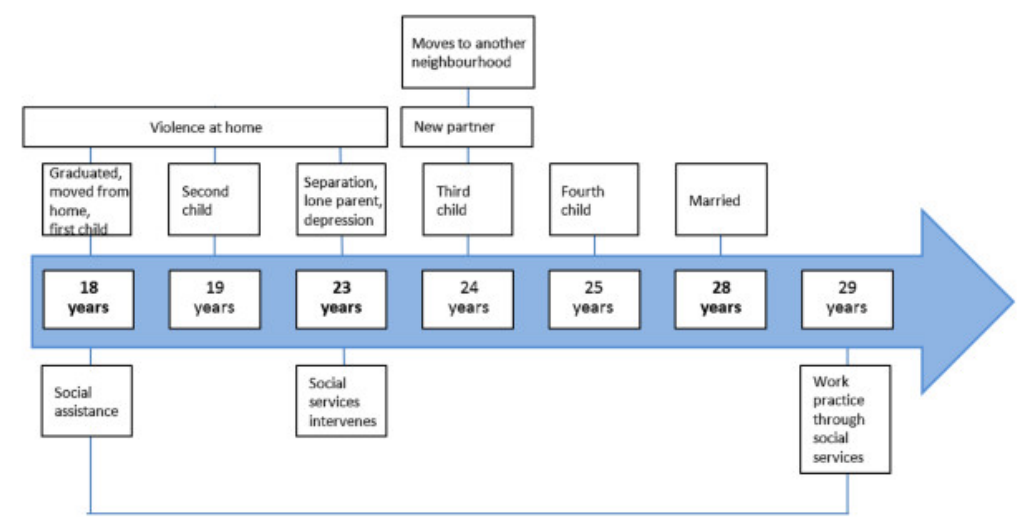

Figure 1. Reform in Education

\section{The Proposed Methodology}

School PE Outward Development significance. Experience in expanding training activities, teacher training has been put before the training content, objectives, requirements, and safety issues make it clear to the students, the activities generally not talk, do not participate in the discussion, full respect for the dominant position of students and initiative. Summary after the event, the discussion mainly concerned by the students themselves, teachers only appropriate guidance and summary. Operation of the entire training activities experiences and summarized by the students themselves to complete. Therefore, this kind of learning and training methods promote a human subject can be a good development of human potential, to cultivate students' practical ability and innovative spirit, has a positive role in promoting.

Outward Bound its unique way, the content and characteristics, to improve students' resistance to frustration and failure of mental endurance. Outward Bound is a specific environment and atmosphere, students should continue to overcome their psychological fear, emotion regulation and self-regulation to improve the ability to maintain peace of mind, the courage to challenge themselves, overcome their own, which create calm, resolute, indomitable good willpower. Such as "trust fall back" This project requires students to fall back on 1.6-meter-high platform straight body fell backward, other group members in the audience fell back Stretch your arms to do the protection, catch the fallen students. Students can promptly adjust their mentality to exclude Language altitude disturbances that can easily complete this project to improve the mental interference. Outward Bound is traditional educational neglect mental quality training is an important supplement can effectively improve the students' mental health. Foster the development of team spirit. Expand training team allows each student in a common goal to experience success and failure, fun and bitterness, honed willpower, team strength, to understand the importance of teamwork in participation, to appreciate the significance of teamwork, there conducive to the collective sense of honor students and social responsibility; to enable students to learn and develop objective evaluation of their own in training, to make themselves and others, and community groups to maintain a harmonious relationship, to enable students to improve the ability to adapt to society in exchange and cooperation .

Help to stimulate students' potential and foster innovation and creativity. Many projects are to expand the training to train student creative thinking and design, on the strength of the participants, intellectual, psychological is a severe test.

Traditional school sports seriously out of student life, the lack of contact with modern social and technological development. The introduction of new sports is an important way sports curriculum 
resources development and utilization. Outward Bound flexible way, novel and unique, rich content, financial interest and knowledge in one of the many projects reflect the modern return to nature, thrill-seeking, the courage to explore, dare to challenge, entertainment and other psychological, it has a strong attraction force, can stimulate students' enthusiasm. Outward Bound into the school sports, you can change the physical education curriculum to some extent, too much emphasis on health knowledge and skills to strengthen ties student life, improve students 'interest, to strengthen the role of sport in improving students' mental health, content-rich sports programs system, physical education curriculum reflects modern life of the current characteristics, in line with the development trend of curriculum reform.

It helps to change the way of learning. By the traditional concept of the impact of the curriculum to discipline centered in the implementation of the school curriculum for middle school students did not receive due attention, students are passive and mechanical. Outward Bound is an experiential learning approach, which advocates active participation of students, willing to explore and practice, emphasis on emotional experience of students, to enable students to participate fully in the process of learning to appreciate fun. It also emphasizes team learning, helping to train students' ability to acquire knowledge, hands-on ability, analysis and capacity and ability to communicate and cooperate to solve the problem and so on. Outward Bounded this education in line with current trends of education reform, the promotion of traditional mode of education reform is of great significance.

School Sports feasibility of introducing expand training. Students are required to enter the Outward Bound School Sports premise. Students do not like gym class, not because they do not like sports, mainly due to the course content to inspire students' passion for learning, and therefore the main school sports urgent need to absorb the introduction of appropriate content into the PE class. Expand training content, means very rich, and more for a unique scene conscious cleverly designed, it changed the traditional sports teaching a single, boring form of organization, making sports more vivid and lively. Expand the training and physical organic integration, in line with the "health first" school sports thinking, and promoting the overall development of students.

Outward Bound is the own advantages into the basic school sports. Outward Bound is to achieve a specific purpose can be pre-designed activities to enrich its content, flexible manner, similar to games, fun and financial knowledge in one, can stimulate students' enthusiasm, to enable students to actively participate in the activities. Expand training required space, equipment is relatively simple, it is easy to reach, any one school can meet, it does not require the standard track and field, or even only one classroom space or it can be done to expand the training.

Reform of PE Outward Bound course content makes it possible to enter the school. New physical education curriculum reform, especially the reform of the physical education curriculum content into the curriculum for the new sports provide a basis for policy. Outward Bound is to expand the school's physical education curriculum, is a useful complement to sports activities, a new classroom students quality education.

The majority of PE teachers have the ability to expand the implementation of training. Teachers organize, monitor, guide and inductive ability to expand the training school sports is the key. The majority of sports teachers with extensive teaching experience, knowledge management, organizational behavior, psychology and other aspects also have a certain understanding, if they accept the simple training and learning are fully competent to expand teaching training.

Expand the training and physical similarities. Outward Bound's goal is to enable students to fully understand their own potential, to develop good psychological quality and courage, indomitable will of the quality; enhance the power of the players on the team awareness, training students a sense of belonging, develop collective ideas, innovation and environmental awareness, etc. .

Based on Outward Bound school sports and objectives of analysis and comparison, both in large part it has a certain unity, its essence is the same, people are focusing on the shape, promote the comprehensive development of man.

Outward Bound into the significance of school. Good relationships rely on good communication and mutual trust to be formed, maintained would double the project, communication project digital transmission, tear, trust take a walk, trees and squirrels and other methods used in 
school sports, so that students experience in practice, lack of communication and two-way communication brought different results and different feelings, understanding the importance of communication and trust, effective communication to explore ways and means to overcome the exchanges inferiority, fear, jealousy, thereby to establish a good relationship of trust, promote the formation of students' good relationships.

Good team atmosphere and overall awareness, not only make the members of their respective positions on outstanding performance, full play to their potential and make collective calmly face changes and challenges in the process of integration will expand the training of school sports, Note that it is combined with the characteristics and advantages of sports projects, inspire students to experience the pleasure of group activities, so that students understand the importance of cooperation between the individual and the collective experience of symbiotic, relationship between students and students, with the collective wisdom of experience to the joy of success, experience windfall collaborative creation, feel the collective cohesion, thereby contributing to the culture of teamwork.

Expand the training project are space projects, field projects, water projects, the content is rich and varied. For the purpose of training needs, through careful design., Which is incorporated into school physical education class among both rich sports classroom teaching content, improve students' interest in learning, but also conducive to the development of school sports resources to better promote the development of school sports.

\section{Conclusion}

Although school sports and expand the training has similarities and closely linked in many ways, but that is two different concepts, the difference is obvious. In the content into the Outward Bound school sports, to both complement each other, can achieve the purpose of school sports, but also to achieve the purpose of expanding training, win-win results. We will expand the training and physical organic integration, in line with the "health first" school sports thinking, and also promoting the overall development of students. Expand the training and physical contact, although there are many, but not exclusively to expand physical education training course, the two cannot be equated. Outward Bound is to expand the school's physical education curriculum is a useful complement to sports activities, a new classroom student quality education. The introduction of training need to expand the flexibility good organization school grades can be divided, sub-classes, options form and we can arrange the various parts in physical education that may be in the form of clubs can be in the form of competition.

\section{References}

[1] Makivić1, Bojan, et al. "Heart rate variability (HRV) as a tool for diagnostic and monitoring performance in sport and physical activities." J Ex Physiol 16.3 (2013): 103-127.

[2] Kirk, David. Physical Education and Curriculum Study (Routledge Revivals): A Critical Introduction. Routledge, 2014.

[3] Höner, Oliver, and Yolanda Demetriou. "Effects of a health-promotion programme in sixth grade German students' physical education." European journal of sport science 14.sup1 (2014): S341-S351.

[4] Harris, Jo. "Physical education teacher education students' knowledge, perceptions and experiences of promoting healthy, active lifestyles in secondary schools." Physical Education and Sport Pedagogy 19.5 (2014): 466-480.

[5] Heidemann, Malene, et al. "The impact on children's bone health of a school-based physical education program and participation in leisure time sports: the Childhood Health, Activity and Motor Performance School (the CHAMPS) study, Denmark." Preventive medicine 57.2 (2013): 87-91. 